\title{
A Survey of 150 Video-Assisted Thoracoscopic Procedures in Kuwait
}

\author{
Adel K. Ayed Emad Al-Shawaf \\ Department of Surgery, Faculty of Medicine, Kuwait University and Chest Diseases Hospital, Kuwait
}

\section{Key Words}

Blebectomy · Pleural biopsy · Thoracic sympathectomy · Thoracoscopy

\begin{abstract}
Objective: To review our experience of indications, technique, and complications as they relate to video-assisted thoracoscopic surgery (VATS) in the diagnosis and management of intrathoracic diseases. Subjects and Methods: One hundred and fifty consecutive VATS procedures, which were performed over a 3-year period, were retrospectively evaluated. Indications included recurrent or persistent primary spontaneous pneumothorax $(\mathrm{n}=$ 73 patients), lung biopsies for diagnosis of diffuse lung disease $(n=33)$, pleural biopsies $(n=18)$, wedge resections of pulmonary nodules $(n=8)$, bilateral thoracic sympathectomy $(n=6)$, decortication $(n=5)$, mediastinal tumor biopsies ( $n=5)$, excision of bullous emphysema $(n=1)$, and removal of a foreign body from the pleural cavity $(n=1)$. An alternative method of manipulating thoracoscopic instruments without using a trocar is described. Results: Of the 150 VATS procedures, 127 (85\%) were successfully performed, $6(4 \%)$ were converted to thoracotomy and $17(11 \%)$ had complications. The most common complication was prolonged air leak, which occurred in 9 patients. The average postoperative hospi-
\end{abstract}

tal stay was 4 days (range: 2-17). Diagnostic procedures were considered successful in 32 out of 33 lung biopsies and in all 18 patients with pleural diseases, 8 lung nodules, or 5 mediastinal tumor biopsies. The other 86 therapeutic VATS procedures were effective in $82(95 \%)$ patients. Four (5\%) patients had a recurrence of the pneumothorax after VATS. Conclusion: Thoracoscopy and the use of a nontrocar technique is a safe and effective method for the diagnosis and treatment of intrathoracic diseases.

Copyright $@ 2004$ S. Karger AG, Base

\section{Introduction}

With the advent of minimally invasive techniques in thoracic surgery in 1990, video-assisted thoracic surgery (VATS) has become a popular approach strategy and the surgical procedure of choice in the diagnosis and treatment of many pleural and some pulmonary, pericardial, and mediastinal diseases [1-3]. VATS allows complete visualization of the pleural space with evaluation of both the parietal and visceral pleural surfaces. In addition, recent improvement in endoscopic surgical instruments has overcome limitations inherent in conventional surgery. Thoracoscopy, for example, has several advantages over thoracotomy in terms of postoperative pain and pul-

\section{KARGER \\ Fax +4161306 1234 \\ E-Mail karger@karger.ch \\ www.karger.com

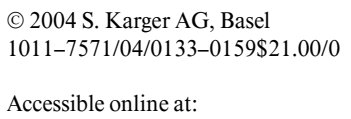

Dr. Adel K. Ayed, Associate Professor

Department of Surgery, Faculty of Medicine

Kuwait University, PO Box 24923

KW-13110 Safat (Kuwait)

Tel. +965 5319475, Fax +965 5319597, E-Mail adel@hsc.kuniv.edu.kw 
Table 1. Types of VATS procedures during the 3-year study period

\begin{tabular}{lcc}
\hline \multirow{2}{*}{ Types of procedures } & \multicolumn{2}{l}{ Patients } \\
\cline { 2 - 3 } & $\mathrm{n}$ & $\%$ \\
\hline Wedge excision and mechanical pleurodesis & 73 & 48.7 \\
Wedge excision & 41 & 27.3 \\
Pleural biopsy & 18 & 12 \\
Bilateral thoracic sympathectomy & 6 & 4 \\
Decortication & 5 & 3.3 \\
Biopsy of mediastinal mass & 5 & 3.3 \\
Excision of bullae & 1 & 0.7 \\
Removal of foreign body & 1 & 0.7 \\
\hline Total & 150 & 100 \\
\hline
\end{tabular}

monary dysfunction [4]. It also provides a wider and unlimited operative field of vision.

While numerous authors have reported their experience with VATS in developed countries $[1,3,5,6]$, little has been reported elsewhere. In this study, we describe our experience in Kuwait using the VATS technique for a variety of intrathoracic disorders.

\section{Subjects and Methods}

Videothoracoscopy procedures were performed on 150 patients between January 1996 and December 1998 at the Chest Diseases Hospital in Kuwait. There were 125 male and 25 female patients, with a mean age of 33 years (range 13-72 years). Information collected for each patient included demographic data, indications, type of procedures, incidence of conversion to thoracotomy and complications. The types of procedures performed are summarized in table 1 . The most common procedure, wedge excision and mechanical pleurodesis for recurrent or persistent spontaneous pneumothorax, was used in 73 (68 males and 4 females), followed by wedge excision only in 41 patients ( 26 male and 15 female, mean age 39 years, range 13-70 years). Of these 41,33 had lung biopsy of diffuse pulmonary infiltrates and 8 excision of a solitary pulmonary nodule. VATS was performed to remove an intravenous catheter from the pleural cavity and on another to excise big bullae. In 6 patients, VATS was converted to a thoracotomy. The reasons for conversion included inability to collapse the lung in 2 cases, finding a lesion in 1 , control of bleeding in 1 , adhesions in the pleural space in 1 and equipment failure in 1 .

All procedures were performed under general anesthesia in the operating room using a double-lumen endotracheal tube. The patients were placed in the lateral position for all procedures. A $10-\mathrm{mm}$ trocar was inserted through the seventh intercostal space in the midaxillary line to create access for the thoracoscope and camera. A 10-mm, 0-degree rigid thoracoscope (Karl Storz, Tuttlingen, Germany) and camera attached to a video monitor was then inserted.
Exploratory videothoracoscopy was then performed to identify any pleural, lung, or mediastinal pathology. After localizing the lesion or the site of biopsy, another two incisions were made close to the lesions. The incisions, placed in the anterior and posterior axillary lines, were usually $1.5-2 \mathrm{~cm}$ to allow for direct passage of conventional thoracic or long thoracoscopic instruments without placement of trocars. Wedge excisions and biopsies were taken using a reloadable 35-mm Autosuture Endo GIA stapler, United States Surgical Corp., Norwalk, Conn., USA.

In cases of biopsy of mediastinal tumors, wedge excision of pulmonary nodules, and pleural biopsies, plastic bags were used to retrieve the tissues. Pleurodesis was performed using a gauze swab to rub the pleura in different places. Following the procedure, a $28 \mathrm{~F}$ intercostal tube was inserted through the inferior incision in the seventh intercostal space in the pleural cavity.

VATS was used for pneumothorax, interstitial lung disease and pleural effusion in more than $120(80 \%)$ of the cases. VATS was also used for excision of solitary pulmonary nodules and treatment of idiopathic hyperhydrosis.

\section{Results}

The overall complication rate was $11.3 \%$. The most common complication, persistent air leak (longer than 5 days), occurred in 9 patients (6\%) and required prolonged pleural drainage. There was no mortality in this series. The mean operative time for all procedures was $65 \mathrm{~min}$ and the mean length of hospital stay for all patients was 4 days (range $2-17$, table 2 ).

\section{Wedge Excision and Mechanical Pleurodesis for Pneumothorax}

Of the 73 patients who underwent a VATS wedge excision and mechanical pleurodesis for recurrent or persistent primary spontaneous pneumothorax, $66(90 \%)$ procedures were successfully done, 1 patient required conversion to open thoracotomy because of bleeding from the intercostal blood vessel and 6 patients had complications. Of these 6 patients, 5 had persistent air leak and 1 subcutaneous emphysema. Four recurrences (5.4\%) were noted after a mean follow-up of 42 months (range 36-54). The recurrences occurred in the first year of follow-up. Three required a reoperation and 1 was treated by rest without pleural drainage.

\section{Wedge Excision Only}

Of the 41 patients that had wedge excision only, 32 $(78 \%)$ were treated successfully, 3 needed conversion to an open procedure and 6 had complications. Of the 3 patients that required conversion to thoracotomy, 1 was due to a deep nodule and the other 2 were due to stiff lung. Of the 6 with complications there was prolonged air leak 
Table 2. Summary of data about specific VATS procedures

\begin{tabular}{|c|c|c|c|c|c|c|c|}
\hline \multirow[t]{2}{*}{ Procedure } & \multirow[t]{2}{*}{$\mathrm{n}$} & \multirow{2}{*}{$\begin{array}{l}\text { Conver- } \\
\text { sion }\end{array}$} & \multirow{2}{*}{$\begin{array}{l}\text { Compli- } \\
\text { cations }\end{array}$} & \multicolumn{2}{|c|}{ Operative time, $\min$} & \multicolumn{2}{|c|}{ Postoperative stay, days } \\
\hline & & & & mean & range & mean & range \\
\hline Wedge excision and pleurodesis & 73 & 1 & 6 & 56 & $30-90$ & 4 & $3-13$ \\
\hline Wedge excision & 41 & 3 & 6 & 57 & $20-120$ & 3 & $2-8$ \\
\hline Pleural biopsy & 18 & 1 & 2 & 49 & $25-75$ & 4 & $2-12$ \\
\hline Sympathectomy & 6 & 0 & 0 & 110 & $90-120$ & 2 & $2-3$ \\
\hline Biopsy of mediastinal mass & 5 & 0 & 0 & 64 & $40-100$ & 4 & $3-6$ \\
\hline Decortication & 5 & 1 & 3 & 124 & $90-150$ & 7 & $5-14$ \\
\hline Excision of big bullae & 1 & 0 & 0 & - & & - & \\
\hline Removal of foreign body & 1 & 0 & 0 & - & & - & \\
\hline Total & 150 & 6 & 17 & - & & - & \\
\hline
\end{tabular}

in 3 patients, persistent pleural effusion in 2 and subcutaneous emphysema in 1 patient. The preoperative indication was a pulmonary infiltrate in 33 and nodules in 8 cases. Pathologic examination revealed a benign disease in 36 patients and a malignant lesion in 4 . One patient remained undiagnosed. The procedure lasted $57 \pm 25$ min. The mean duration of chest tube drainage was 2 days (range 1-7). The mean hospital stay, including patients who were converted to thoracotomy, was $3 \pm 2$ days.

\section{Pleural Biopsy}

VATS was done to obtain pleural biopsy specimens in 18 patients, whose mean age was 43 years (range, 18-70) years. The procedure was successful in $15(83 \%)$ patients, 1 had conversion to an open procedure due to adhesions and 2 had complications that consisted of persistent pleural drainage in 2 patients. Pathologic studies disclosed tuberculosis in 11 patients, chronic pleuritis in 5, mesothelioma in 1, and metastatic carcinoma in 1 patient. The mean operating time was $49 \pm 16 \mathrm{~min}$, and length of hospital stay was $4 \pm 2$ days.

\section{Sympathectomy}

VATS sympathectomy was successfully performed on 6 patients ( 5 male, 1 female). No patient required conversion to an open procedure and there were no postoperative complications. The indication in all patients was hyperhydrosis. All patients underwent bilateral thoracic sympathectomy. The mean operative time and mean duration of hospitalization were $110 \mathrm{~min}$ (range 90-120) and 4 days (range 3-6), respectively. At follow-up, all patients had warm, dry hands.

Thoracoscopy for Intrathoracic Diseases

\section{Miscellaneous}

All the 5 patients who underwent a biopsy of mediastinal masses were successful. Pathologic studies disclosed lymphoma in 4 patients and thymoma in 1 . Of another 5 patients who had decortication for empyema, 1 was converted to thoracotomy due to extensive adhesions while 3 had complications that consisted of bleeding in 1, prolonged air leak in another and persistent pleural effusion in the remaining patient. Excision of big bullae (1 patient) and removal of a plastic foreign body (1 patient) were successfully done.

\section{Discussion}

The application of VATS in thoracic surgery is becoming an accepted modality of treatment $[1,3,5,6]$ as many procedures have been shown to be technically feasible. In our experience, VATS was useful for diagnosis (pleural effusion and indeterminate pulmonary nodules), biopsy (diffuse pulmonary infiltrate), and treatment (pleural effusion, recurrent or persistent spontaneous pneumothorax, resulting in safe and effective thoracic sympathectomy).

The major indications for VATS are treatment of pneumothorax and excision of pulmonary nodules [5-9]. In this study the primary indication was pneumothorax (48.7\%) followed by wedge resection of the lung $(27.3 \%)$, similar to a Belgian study [8] in which treatment of pneumothorax and wedge resection of the lung were 49 and $12 \%$, respectively. However, Allen et al. [5] reported that $43 \%$ of VATS was performed for excision of pulmonary nodules, the other major indication for VATS. In this

Med Princ Pract 2004;13:159-163 
study, thoracoscopy was successful in the majority (85\%) of the patients in whom it was attempted and the preoperative goals of the procedure were satisfied in these patients. Therapy such as bleb excision [10-13], lung biopsy [1, 14-16], pleural biopsy [17-19], debridement of empyema $[5,6,20]$ or curative resection of a solitary pulmonary nodule $[5,6,21,22]$, was added to patient management and prevented subsequent thoracotomy. Similarly, Mack et al. [23] have reported that VATS was an acceptable approach for the diagnosis of indeterminate pulmonary nodules and of anterior and posterior mediastinal masses, and for the management of early empyema, clotted hemothoraces, secondary pneumothorax, limited lung cancer treatment, and benign esophageal disease. On the other hand, VATS was thought to be unacceptable or investigational for a majority for thymectomy, lobectomy and lung volume reduction operations [6, 23, 24].

Despite the benefits of VATS, manipulation of the instruments and exposure are limited using the trocar method. We found that manipulation of thoracoscopic and some conventional thoracic instruments was easier and that they passed through the incisional wound in less time without using a trocar. In addition, the ability to feel the lung lesion was not reduced. Liu et al. [25] described a similar technique, 'extended manipulating channel', in which 3- to 4-cm transverse incisions and conventional thoracic instruments were used. Their technique was effective in performing a broad spectrum of thoracic procedures.

The need for conversion has been reported to be between 4.1 and $33.1 \%$, depending on the procedure [5, 6 , 26-28]. These findings are consistent with our experience, where $4 \%$ of patients required conversion to an open procedure. The reasons for converting were inability to find a lesion or the presence of a lesion in a difficult location for thoracoscopic resection, tight adhesions in the pleural space, equipment failure, major bleeding, and/or a stiff lung [29]. Although other reported series showed higher conversion rates than ours [5,7], they could be due to the fact that VATS was frequently done for malignant pulmonary nodules or masses, where conversion to an open procedure is necessary to ensure adequate resection, keeping morbidity low. In our study, VATS was done most commonly for spontaneous pneumothorax, for which conversion is very infrequent.

There were no operative deaths in our series. Reported in-hospital mortality rates ranged between 0 and $5 \%[3,7$, $26,27]$, with the deaths largely involving older patients in poor condition or with malignancy. Most surgical series have reported an incidence of $4-11 \%$ of complications resulting from VATS [3, 26-28]. Most of the postoperative complications seen after thoracoscopy are similar to those that occur after open procedures. The most common complication, prolonged air leak, which occurred in $6 \%$ of the patients in our series, was related mainly to the large number of cases performed for spontaneous pneumothorax and lung biopsy. The cause of the air leak was either an air leak from the row of the staples or missed bullous areas, suggesting that the resection of the bullous areas must be meticulously performed and that the entire lung should be inspected for other bullae.

The potential advantages of VATS for thoracoscopy as compared to thoracotomy are many. The small incisions ensure that major muscles are not divided, and since the ribs are not spread, fracture is rare, resulting in far less postoperative pain as observed in this study. There may also be less compromise of pulmonary function. Previous reports showed that VATS accelerated recovery and allowed patients to move and ambulate without difficulty [30]. In this study, the mean hospital stay was only 4 days (range 2-17 days). Only small doses of analgesics were needed, and most patients returned to preoperative levels of activity after only 2 weeks. Except for patients with effusions and prolonged air leak, the duration of chest tube use was short, also shortening the length of the postoperative hospital stay (which is determined mainly by the duration of the chest tube drainage).

\section{Conclusion}

Our results show that thoracoscopy has an important role in the diagnosis and treatment of many thoracic diseases. The procedure is useful in the treatment of pneumothorax and for taking lung and pleural biopsies. Its use is associated with shorter hospital stay and rapid return to normal activity. Moreover, the procedure and the use of a nontrocar technique is safe, as shown by a low complication rate. 


\section{References}

1 Mack MJ, Aronoff RJ, Acuff TE, Douthit MB, Bowman RT, Ryan WH: Present role of thoracoscopy in the diagnosis and treatment of diseases of the chest. Ann Thorac Surg 1992;54: 403-409.

2 Naunheim KS, Mack MJ, Hazelrigg SR, Feruson MK, Ferson PF, Boley TM, Landreneau RJ: Safety and efficacy of video-assisted thoracic surgical techniques for the treatment of spontaneous pneumothorax. J Thorac Cardiovasc Surg 1995;109:1198-1204.

3 Lewis RJ, Caccavale RJ, Sisler GE, Mackenzi JW: One hundred consecutive patients undergoing video-assisted thoracic operations Ann Thorac Surg 1992;54:421-426.

4 Landreneau RJ, Hazelrigg SR, Mack MJ, Dowling RD, Burke D, Gavlick J, Perrino MK, Ritter PS, Bowers CM, DeFino J, Nunchuck SK, Freeman J, Keenan RJ, Ferson PF: Postoperative pain-related morbidity: Video-assisted thoracic surgery versus thoracotomy. Ann Thorac Surg 1993;56:1285-1289.

5 Allen MS, Deschamps C, Jones DM, Trastek VF, Pairolero PC: Video-assisted thoracic surgical procedures: The Mayo experience. Mayo Clin Proc 1996;71:351-359.

6 Rovario GC, Varoli F, Vergani C, Maciocco M: State of the art in thoracoscopic surgery: A personal experience of 2000 videothoracoscopic procedures and an overview of the litrature. Surg Endosc 2002;16:881-892.

7 Hazelrigg SR, Nunchuck SK, LoCicero J 3rd: Video assisted thoracic surgery study group data. Ann Thorac Surg 1993;56:1039-1044.

8 Coosemans W, Lerut TE, Van Raemdonck DE: Thoracoscopic surgery: The Belgian experience. Ann Thorac Surg 1993;56:721-730.

9 Petrakis I, Katsamouris A, Drossitis I. Bouros D, Chalkiadakis G: Usefulness of thoracoscopic surgery in the diagnosis and management of thoracic diseases. J Cardiovasc Surg 2000;41: 767-771.
10 Inderbitzi RGC, Leiser A, Furrer M, Althaus $\mathrm{U}$ : Three years' experience in video-assisted thoracic surgery (VATS) for spontaneous pneumothorax. J Thorac Cardiovasc Surg 1994;107: 1410-1415.

11 Liu HP, Lin PJ, Hsieh MJ, Chang JP, Chang $\mathrm{CH}$ : Thoracoscopic surgery as a routine procedure for spontaneous pneumothorax: Results from 82 patients. Chest 1995;107:559-562.

12 Hazelrigg SR, Landreneau RJ, Mack M, Acuff T, Seifert PE, Auer JE, Magee M: Thoracoscopic stapled resection for spontaneous pneumothorax. J Thorac Cardiovasc Surg 1993;105: 389-393.

13 Yim AP, Ho JK, Chung SS, Ng DC: Videoassisted thoracoscopic surgery for primary spontaneous pneumothorax. Aust NZ J Surg 1994;64:667-670.

14 Krasna MJ, White CS, Aisner SC, Templeton PA, McLaughlin JS: The role of thoracoscopy in the diagnosis of interstitial lung disease. Ann Thorac Surg 1995;59:348-351.

15 Zegdi R, Azorin J, Tremblay B, Destable MD, Lajos PS, Valeyre D: Videothoracoscopic lung biopsy in diffuse infiltrative lung disease: A 5year surgical experience. Ann Thorac Surg 1998;66:1170-1173.

16 Merriman TE, Corbet JD: Thoracoscopy: A useful diagnostic and therapeutic procedure. Aust NZ J Surg 1993;63:454-458.

17 Yim AP, Ho JK, Lee TW, Chung SS: Thoracoscopic management of pleural effusions revisited. Aust NZ J Surg 1995;65:308-311.

18 Hucker J, Bhatnagar NK, Al-Jilaihawi AN, Forrester-Wood CP: Thoracoscopy in the diagnosis and management of recurrent pleural effusions. Ann Thorac Surg 1991;52:1145-1147.

19 Menzies R, Charbonneau M: Thoracoscopy for the diagnosis of pleural disease. Ann Intern Med 1991;114:271-276.
20 Krasna MJ, McLaughlin JS: Efficacy and safety of thoracoscopy for diagnosis and treatment of intrathoracic disease: The University of Maryland experience. Surg Laparosc Endosc 1994;4: 182-188.

21 Landreneau RJ, Hazelrigg SR, Ferson PF Johnson JA, Nawarawong W, Boley TM, Curtis JJ, Bowers CM, Herlan DB, Dowling RD: Thoracoscopic resection of 85 pulmonary lesions. Ann Thorac Surg 1992;54:415-420.

22 Allen MS, Deschamps C, Lee RE, Trastek VF, Daly RC, Pairolero PC: Video-assisted thoracoscopic stapled wedge excision for indeterminate pulmonary nodules. $\mathbf{J}$ Thorac Cardiovasc Surg 1993; 106:1048-1052.

23 Mack MJ, Scruggs GR, Kelly KM, Shennib H, Landreneau RJ: Video-assisted thoracic surgery: Has technology found its place? Ann Thorac Surg 1997;64:211-215.

24 Yim AB, Lee TW, Izzat MB, Wan S: Place of video-thoracoscopy in thoracic surgical practice. World J Surg 2001;25:157-161.

25 Liu HP, Lin PJ, Chang JP, Chang CH: Videoassisted thoracic surgery: Manipulation without trocar in 112 consecutive procedures. Chest 1993; 104:1452-1454.

26 Jancovici R, Lang-Lazdunski L, Pons F, Cador L, Dujon A, Dahan M, Azorin J: Complications of video-assisted thoracic surgery: A fiveyear experience. Ann Thorac Surg 1996;61: 533-537.

27 Kaiser LR, Bavaria JE: Complications of thoracoscopy. Ann Thorac Surg 1993;56:796-798.

28 Krasna MJ, Deshmukh S, McLaughlin JS Complications of thoracoscopy. Ann Thorac Surg 1996;61:1066-1069.

29 Stoica SC, Walker WS: Video assisted thoracoscopic surgery. Postgrad Med J 2000;76: 547-550.

30 Miller JI: The present role and future considerations of video-assisted thoracoscopy in general thoracic surgery. Ann Thorac Surg 1993;56: 804-806. 